\title{
THE USE OF A TRANSPORT SIMULATION MODEL (AIMSUN) TO DETERMINE THE ENVIRONMENTAL EFFECTS OF PEDESTRIANIZATION AND TRAFFIC MANAGEMENT IN THE CENTER OF THESSALONIKI
}

\author{
EVANGELOS MINTSIS ${ }^{1}$, MICHAEL BELIBASSAKIS ${ }^{2}$, GEORGE MINTSIS ${ }^{2}$, \\ SOCRATES BASBAS ${ }^{2, *}$, and MAGDA PITSIAVA-LATINOPOULOU 3
}

\footnotetext{
${ }^{1}$ Centre for Research and Technology Hellas - Hellenic Institute of Transport, 57001 Thermi, Thessaloniki, Greece

${ }^{2}$ Faculty of Rural and Surveying Engineering, Aristotle University of Thessaloniki, 54124 Thessaloniki, Greece

${ }^{3}$ Faculty of Civil Engineering, Aristotle University of Thessaloniki, 54124 Thessaloniki, Greece

*Corresponding author: smpasmpa@auth.gr
}

\begin{abstract}
Traffic congestion in urban areas results in increased energy consumption and vehicle emissions. Traffic management that alleviates traffic congestion also mitigates the environmental effects of vehicular traffic. This study uses the transport simulation model AIMSUN to evaluate the environmental effect of a set of traffic management and pedestrianization schemes. The effects of the pedestrianization of specific sections of roads, converting two-way roads into one-way roads for traffic and changing the direction of flow of traffic along one-way roads were simulated for different areas of Thessaloniki's city centre network. The assessment of the environmental effect was done by determining the predicted fuel consumption and emissions of greenhouse gases (GHG) and air pollutants. Fuel consumption and the environmental indicators were quantified directly using the fuel consumption and emissions model in AIMSUN. A typical weekday morning peak period, between 09:00am-10:00am, was simulated and the demand data obtained using a macroscopic traffic assignment model previously developed for the wider area of Thessaloniki. The results presented in this paper are for network-wide simulation statistics (i.e. fuel consumed, carbon dioxide $\left(\mathrm{CO}_{2}\right)$, nitrogen oxides $\left(\mathrm{NO}_{x}\right)$ and particulate matter $(\mathrm{PM})$ ).
\end{abstract}

Keywords: environment, pedestrianization, traffic management, microscopic simulation, emissions model, AIMSUN

doi: $10.14712 / 23361964.2016 .5$

\section{Introduction}

Pedestrianization is defined as the closing of specific segments of roads to traffic, followed by paving the area and installing street furniture and other details (Hall and Hass-Klau 1985). Pedestrianization schemes aim to promote awareness of the historic environment of cities and increase the value of properties located within traffic-free areas (Chiquetto 1997). However, restricting traffic flow in specific parts of a road network can have substantial implications for local and network-wide environmental conditions. Since traffic flow and speed are the main determinants of levels of air pollution, changes in the patterns of traffic flow inevitably induce changes in the patterns of traffic emissions and fuel consumption (Chiquetto 1997).

There is a study using a mesoscopic traffic simulation model to evaluate the effects of pedestrianization in the city of Chester, UK (Chiquetto and Mackett 1995). Simulation outputs from SATURN (i.e. vehicle queues, traffic flow and travel times) have been used to feed environmental predictive models for estimating traffic emissions. Concurrently, there is an assessment of travellers' response to changes imposed on traffic conditions with respect to mode choice. The results indicate that total fuel consumption slightly decreased, and emissions decreased around the pedestrianized area but increased in the network as a whole.
There is another study that evaluate the effects of pedestrianization on traffic and the environment in the cities of Katerini and Rhodes, Greece (Pitsiava-Latinopoulou and Basbas 2000). This study determined the operation of junctions located near to the main area of pedestrianization using the program SIDRA (Signalized Intersection Designs and Research Aid). The results of this analysis indicated that $\mathrm{NO}_{\mathrm{x}}, \mathrm{HC}$ and $\mathrm{CO}$ emissions decreased significantly along with fuel consumption and average delay per vehicle. In addition, a reduction in road accidents was also recorded near the pedestrianized area.

The change in the performance of traffic (e.g. mean network speed, vehicle-km travelled, etc.) and in environmental indicators (e.g. $\mathrm{CO}_{2}$ emissions, fuel consumption) after the implementation of pedestrianization schemes in urban areas was assessed for all of the traffic and public transport separately using the traffic mesoscopic simulation model SATURN (Taxiltaris et al. 2002). Findings of this analysis indicate an increase in fuel consumption and emissions in the wider area around the pedestrianized zone. It is proposed that traffic demand management schemes and promotion of public transport should complement pedestrianization and counter their potential negative effects.

The environmental effects of pedestrianization of a major arterial street, as part of an architectural proposal for restoring a Square in Thessaloniki, was evaluated using the traffic simulation model SATURN (Economou 
et al. 2002). The authors propose the implementation of mitigating measures (e.g. rearrangement of specific traffic signals, alterations in the circulation patterns in the streets around the square) to alleviate the adverse environmental effects of pedestrianization on nearby streets. An ex-ante evaluation of an urban regeneration project in Athens, Greece (i.e. pedestrianization of a major artery in a downtown area) was conducted to identify the effects of traffic (Kepaptsoglou et al. 2015). The findings indicate that traffic conditions would deteriorate in the short-run, but a potential reduction in traffic resulting from this project could significantly improve traffic and environmental conditions in downtown Athens.

Several studies have been done to assess traffic and environmental effects of other traffic management schemes such as conversion of a two-way road to oneway road, changing the direction of flow of traffic along a one-way road and traffic calming measures. Traffic calming combines physical changes in road design and speed management in order to improve road safety, especially for users of non-motorized transport sharing the same road (Lockwood 1997). Traffic calming measures eliminate conflicting movements, improve visibility, reduce exposure and sharpen the attention of drivers (Ewing 1999).

Specifically, a study in Montreal, Canada investigated the effects of isolated traffic calming measures both at corridor and network levels (Ghafghazi and Hatzopoulou 2014). This study was based on the development of a simulation model of a dense urban neighbourhood. The results of this study indicate that on average, isolated calming measures increase carbon dioxide $\left(\mathrm{CO}_{2}\right)$, carbon monoxide $(\mathrm{CO})$ and nitrogen oxide $\left(\mathrm{NO}_{\mathrm{x}}\right)$ emissions by $1.5,0.3$ and $1.5 \%$, respectively, across the entire network. Area-wide schemes result in a percentage increase of $3.8 \%$ for $\mathrm{CO}_{2}, 1.2 \%$ for $\mathrm{CO}$ and $2.2 \%$ for $\mathrm{NO}_{\mathrm{x}}$ across the entire network.

The effects of two traffic management measures (i.e. speed limit reduction and coordinated traffic lights) is reported for an area of Antwerp, Belgium (Madireddy et al. 2011). An integrated model was used that combined the traffic simulation model Paramics with the $\mathrm{CO}_{2}$ and $\mathrm{NO}_{\mathrm{x}}$ emission model VERSIT + . This predicted that when speed limits are lowered from 50 to $30 \mathrm{~km} / \mathrm{h}$ in the residential part of the study area $\mathrm{CO}_{2}$ and $\mathrm{NO}_{\mathrm{x}}$ emissions are reduced to about $25 \%$ and, in addition, the implementation of a green wave signal coordination scheme along an urban arterial road a further reduction in the order of $10 \%$ could be expected.

The environmental effects of three different traffic management measures (i.e. optimisation of traffic signals, coordination of traffic signals and urban tolling) was determined for Thessaloniki's urban road network using the traffic simulation software SATURN (Papaioannou et al. 2000). This analysis indicates that the combined implementation of these measures yields the best results in terms of environmental benefits compared to the isolated deployment of each of the aforementioned strategies.

This study evaluates the environmental effects of pedestrianization schemes in the city centre of Thessaloniki using microscopic traffic simulation. The road network in the central business district of Thessaloniki was simulated in AIMSUN. Aggregate and disaggregate simulation output statistics were obtained by simulation and are presented in this study.

\section{Materials and Methods}

\section{Microscopic Traffic and Emissions Simulation Modelling}

Microscopic traffic simulators can imitate the longitudinal and lateral movement of individual vehicles as they occur in real-life. Their ability to dictate these movements is based on a set of sub-models that replicate a driver's car-following, lane changing and gap acceptance behaviour. Thus, the simulators estimate each vehicle's position, speed and acceleration for every simulation step. The trajectories of the vehicles are then used to estimate fuel consumption and emissions using the corresponding models that are integrated in the microscopic traffic simulation model. A microscopic emission model has been integrated in AIMSUN (Panis et al. 2006). This model is based on empirical measurements that relate vehicle emissions with the instantaneous speed and acceleration of the vehicle. The importance of using microscopic emission models for the assessment of the environmental effects of traffic management and control policies has been explicitly stressed, since this is a complex issue that requires detailed analysis of not only their effect on average speed but also on other aspects of vehicle operation such as acceleration and deceleration (Rakha and Kamalanathsharma 2011).

\section{The Study Site - AIMSUN Model}

A detailed microscopic simulation model was developed of the central business district area of the city of Thessaloniki. The model development was implemented using the AIMSUN microscopic traffic simulator. The simulated network is comprised of 401 sections and 290 junctions; its total length is $42 \mathrm{~km}$ and is depicted in Fig. 1. Among the 290 junctions, 62 are controlled by signals. Forty public transport lines were also simulated along with their corresponding time plans.

Demand was determined by using a macroscopic traffic assignment model developed in VISUM for the wider area of Thessaloniki (Stamos et al. 2013). Field traffic flow data collected from traffic sensors located throughout the road network of Thessaloniki for a onehour morning peak period (i.e. 09:00-10:00 am) of a typical weekday (i.e. Wednesday 15th October 2014) was input into the macroscopic model, which executed the traffic assignment and produced the necessary demand information for the "loading" of the microscopic 


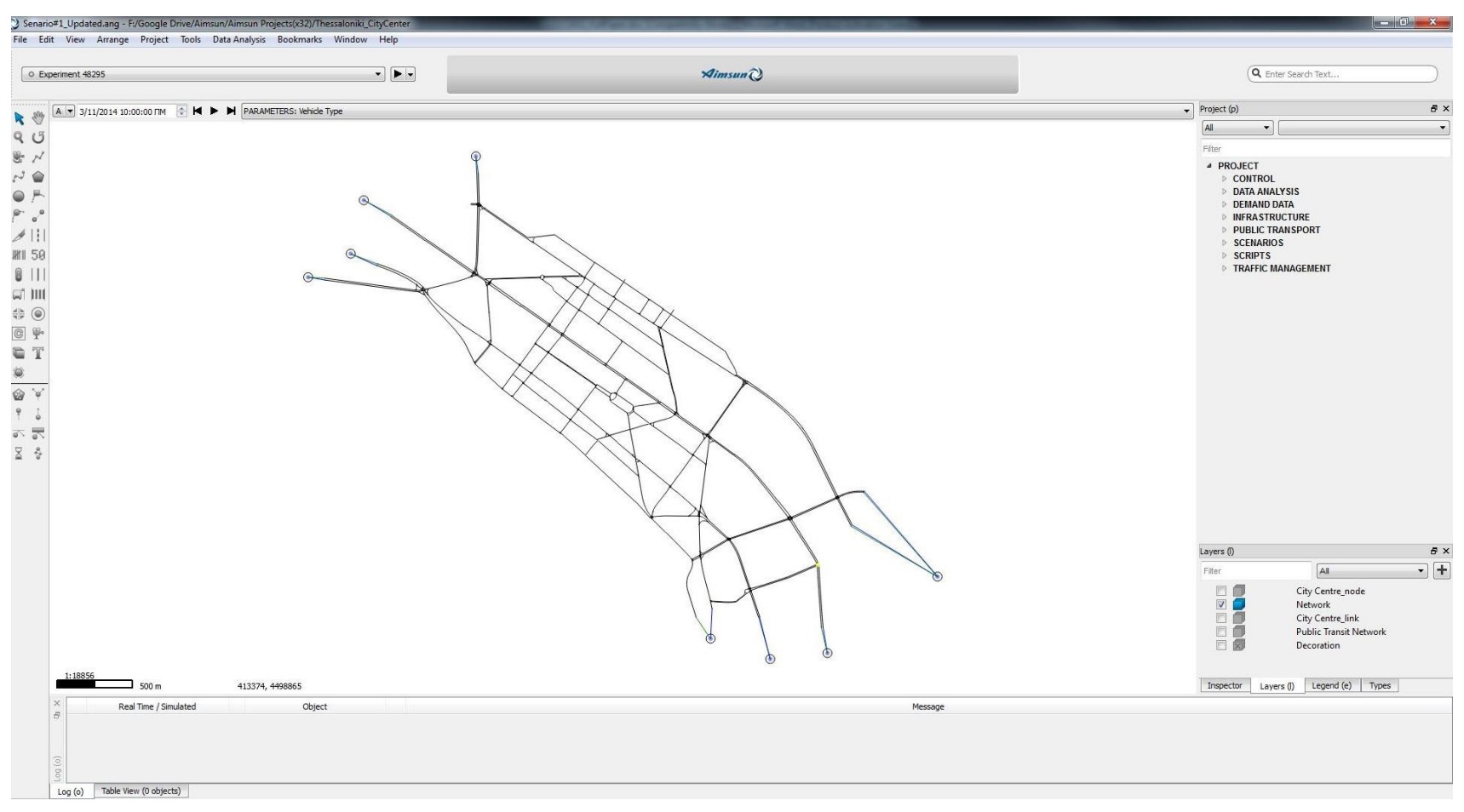

Fig. 1 Simulated network in AIMSUN.

model. Information on traffic composition was also obtained from a previous study (Mitsakis et al. 2013). According to this study the traffic in this portion of Thessaloniki's road network is comprised of $90 \%$ cars, $5 \%$ taxis, $4 \%$ trucks and $1 \%$ buses.

The operation and performance of the network was assessed for five different pedestrianization schemes. A total of 6 scenarios were simulated, 1 pertaining to the base case scenario and 5 to the simulated pedestrian areas. The exact measures involved in each pedestrianization scheme are presented in Table 1.

Table 1 Description of scenarios.

\begin{tabular}{|l|l|}
\hline Scenarios & Descriptions \\
\hline Scenario 1 & $\begin{array}{l}\text { The pedestrianization of A. Sofias St. from Egnatia St. to } \\
\text { Nikis Ave., of Keramopoulou St. from P. loakim St. to A. } \\
\text { Sofias St., of Makenzi King St., of Ermou St. from K. Ntil St. } \\
\text { to A. Sofias St., and the conversion of Ermou St. to a two } \\
\text { lane one-way street from K. Ntil St. to E. Venizelou St. }\end{array}$ \\
\hline Scenario 2 & $\begin{array}{l}\text { The measures of Scenario 1, plus the conversion of } \\
\text { Tsimiski St. to a three lane street, with two general } \\
\text { purpose lanes and one bus lane. }\end{array}$ \\
\hline Scenario 3 & $\begin{array}{l}\text { The pedestrianization of A. Sofias St. from Egnatia St. } \\
\text { to Nikis Ave., of Keramopoulou St. from P. loakim St. } \\
\text { to A. Sofias St., of Makenzi King St., of Ermou St. from } \\
\text { A. Sofias St. to E. Venizelou St., and the conversion of } \\
\text { Ermou St. to a two lane one-way street from K. Ntil St. to } \\
\text { E. Venizelou St. }\end{array}$ \\
\hline Scenario 4 & $\begin{array}{l}\text { The measures of Scenario 1, plus the pedestrianization } \\
\text { of Nikis Ave. from E. Venizelou St. to E. Aminis St. }\end{array}$ \\
\hline Scenario 5 & $\begin{array}{l}\text { The pedestrianization of Nikis Ave. from E. Venizelou St. } \\
\text { to E. Aminis St. and the conversion of Tsimiski St. from } \\
\text { a four lane street to a three lane street, with two general } \\
\text { purpose lanes and one bus lane. }\end{array}$ \\
\hline
\end{tabular}

Due to the stochastic nature of AIMSUN it is necessary to make several runs of each simulated scenario, so that the simulation output is statistically significant. Therefore, five simulations of the base case scenario were initially run, each with a different random seed generated by AIMSUN's internal random number generator, and statistics (i.e. standard deviation and mean value) for the average network speed were determined for this sample of runs. The significance level was selected to be $95 \%$, the tolerable error equal to $0.5 \mathrm{~km} / \mathrm{h}$, and given the standard deviation of the average network speed of the initial sample, the required number of runs was determined to be five.

\section{Results and Discussion}

The output of the simulations includes traffic performance measures and environmental indicators. Simulation output statistics were estimated both at section level (i.e. disaggregated level) and network level (i.e. aggregated). The estimated traffic performance measures are average section traffic flow and average network speed. The environmental indicators are fuel consumption, $\mathrm{CO}_{2}$, $\mathrm{NO}_{\mathrm{x}}$, and PM emissions.

\section{Disaggregated Simulation Output Statistics}

The local effects of pedestrianization were evaluated for three road sections located close to the pedestrianized areas. The implementation of the pedestrianization schemes resulted in the redistribution of traffic in the nearby road network. It becomes apparent from the simulation results that traffic flow along these road sections increases sig- 

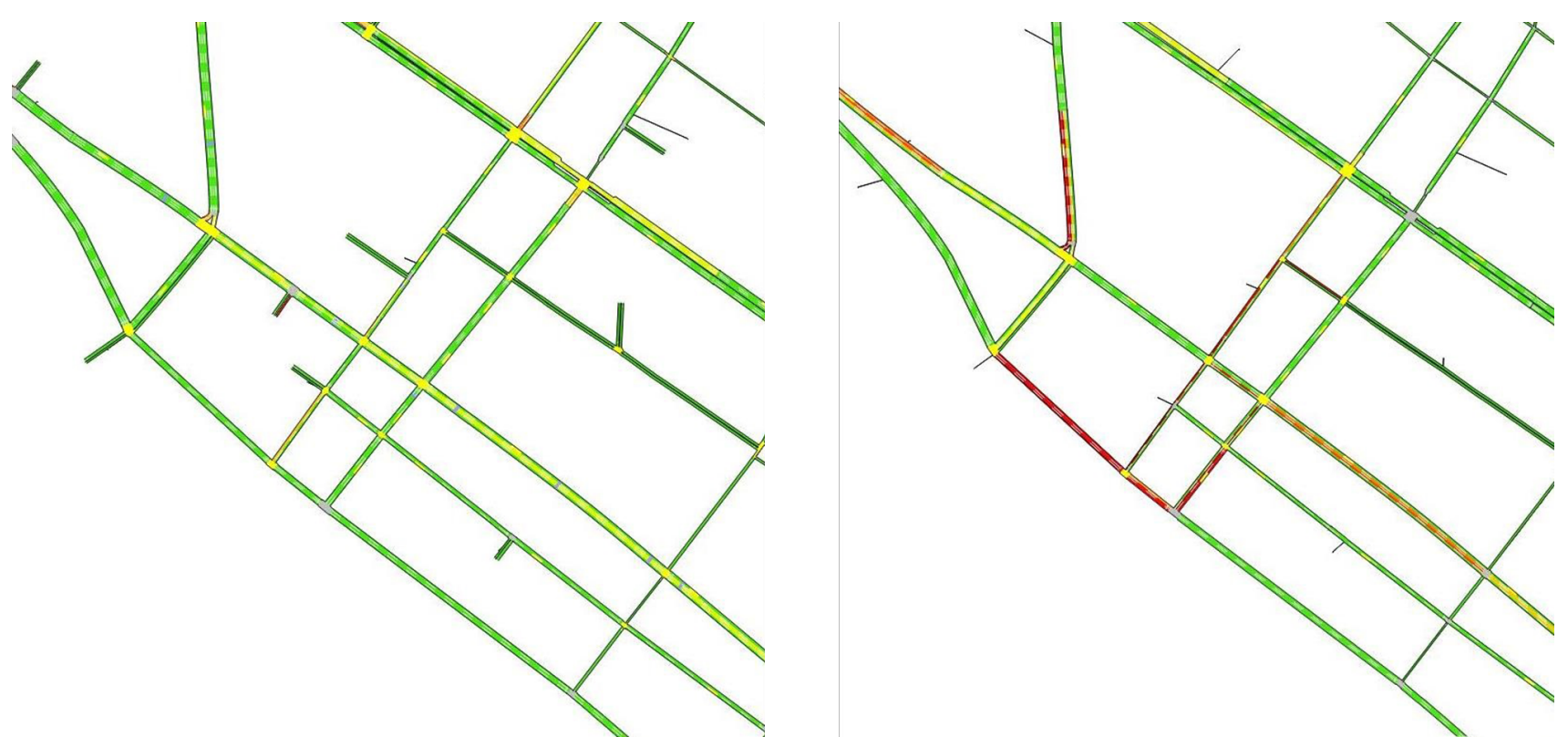

Fig. 2 Pedestranization of Nikis Ave. reduced traffic flow in nearby streets.

nificantly (Table 2) compared to the base case scenario. Consequently, fuel consumption and $\mathrm{CO}_{2}$ emissions also increase substantially (Table 3 and 4). The increase in traffic density on the nearby road network due to the pedestrianization of Nikis Ave. is explicitly depicted in Fig. 2.

Table 2 Difference in average traffic flow relative to that recorded for the base case scenario (\%).

\begin{tabular}{|l|c|c|c|}
\hline $\begin{array}{l}\text { Demand } \\
\text { Level }\end{array}$ & $\begin{array}{c}\text { Tsimiski St. } \\
\text { (upstream } \\
\text { of K. Ntil St.) }\end{array}$ & $\begin{array}{c}\text { Mitropoleos St. } \\
\text { (downstream } \\
\text { of A. Sofias St.) }\end{array}$ & $\begin{array}{c}\text { E.Venizelou St. } \\
\text { (upstream } \\
\text { of Ermou St.) }\end{array}$ \\
\hline Scenario 1 & 76.20 & 11.57 & 62.14 \\
\hline Scenario 2 & 72.02 & 11.10 & 59.44 \\
\hline Scenario 3 & 74.05 & 17.07 & 77.27 \\
\hline Scenario 4 & 72.74 & 74.63 & 85.53 \\
\hline Scenario 5 & 64.74 & 39.93 & 105.64 \\
\hline
\end{tabular}

Table 3 Difference in average fuel consumption relative to that recorded for the base case scenario (\%).

\begin{tabular}{|l|c|c|c|}
\hline $\begin{array}{l}\text { Demand } \\
\text { Level }\end{array}$ & $\begin{array}{c}\text { Tsimiski St. } \\
\text { (upstream } \\
\text { of K. Ntil St.) }\end{array}$ & $\begin{array}{c}\text { Mitropoleos St. } \\
\text { (downstream } \\
\text { of \& A. Sofias St.) }\end{array}$ & $\begin{array}{c}\text { E.Venizelou St. } \\
\text { (upstream } \\
\text { of Ermou St.) }\end{array}$ \\
\hline Scenario 1 & 45.37 & 12.91 & 70.45 \\
\hline Scenario 2 & 38.02 & 16.96 & 70.89 \\
\hline Scenario 3 & 34.93 & 25.32 & 89.52 \\
\hline Scenario 4 & 41.22 & 48.71 & 127.55 \\
\hline Scenario 5 & 41.49 & 34.09 & 112.31 \\
\hline
\end{tabular}

Table 4 Difference in average $\mathrm{CO}_{2}$ emissions relative to that recorded for the base case scenario (\%).

\begin{tabular}{|l|c|c|c|}
\hline $\begin{array}{l}\text { Demand } \\
\text { Level }\end{array}$ & $\begin{array}{c}\text { Tsimiski St. } \\
\text { (upstream of } \\
\text { K. Ntil St.) }\end{array}$ & $\begin{array}{c}\text { Mitropoleos St. } \\
\text { (downstream of } \\
\text { \& A. Sofias St.) }\end{array}$ & $\begin{array}{c}\text { E.Venizelou St. } \\
\text { (upstream of } \\
\text { Ermou St.) }\end{array}$ \\
\hline Scenario 1 & 60.51 & 13.34 & 69.77 \\
\hline
\end{tabular}

\begin{tabular}{|l|c|c|c|}
\hline Scenario 2 & 53.25 & 16.30 & 70.62 \\
\hline Scenario 3 & 56.12 & 24.33 & 87.78 \\
\hline Scenario 4 & 56.70 & 58.41 & 117.48 \\
\hline Scenario 5 & 56.38 & 37.36 & 117.94 \\
\hline
\end{tabular}

\section{Aggregate Simulation of Output Statistics}

The effects of pedestrianization was also assessed network-wide. Since traffic was banned from several road sections, which were converted into pedestrian areas, demand had to be accommodated by the rest of the network. Thus more traffic corresponds to a reduced network capacity and consequently traffic conditions on the whole network deteriorate. The average network speed decreases compared to the base case scenario after the implementation of traffic-free areas (Table 5). Since the average network speed for the base case scenario is $28.23 \mathrm{~km} / \mathrm{h}$, it becomes obvious that the average network speed after pedestrianization is less fuel efficient and environmentally friendly. Network-wide traffic emissions rise significantly as a result of pedestrianization (Table 5). The implemented traffic management schemes effect mainly the emission of particulate matter (PM). The magnitude of PM estimated by the model per scenario is presented in Table 6.

Table 5 Difference in average network statistics relative to those recorded for the base case scenario (\%).

\begin{tabular}{|l|c|c|c|c|}
\hline $\begin{array}{l}\text { Demand } \\
\text { Level }\end{array}$ & Speed & $\mathbf{C O}_{\mathbf{2}}$ & $\mathbf{N O}_{\mathbf{x}}$ & $\mathbf{P M}$ \\
\hline Scenario 1 & -10.99 & 35.54 & 26.05 & 76.70 \\
\hline Scenario 2 & -12.44 & 36.54 & 27.09 & 79.58 \\
\hline Scenario 3 & -10.87 & 34.35 & 24.89 & 73.81 \\
\hline Scenario 4 & -18.31 & 41.08 & 31.14 & 86.65 \\
\hline Scenario 5 & -20.57 & 39.64 & 31.20 & 80.87 \\
\hline
\end{tabular}


Table 6 Magnitude of PM per scenario estimated using the simulation model.

\begin{tabular}{|l|c|}
\hline $\begin{array}{l}\text { Demand } \\
\text { Level }\end{array}$ & PM (kg) \\
\hline Base Case & 726.72 \\
\hline Scenario 1 & 1284.11 \\
\hline Scenario 2 & 1305.03 \\
\hline Scenario 3 & 1263.15 \\
\hline Scenario 4 & 1356.45 \\
\hline Scenario 5 & 1314.43 \\
\hline
\end{tabular}

\section{Conclusions}

The environmental effects of pedestrianization in the city centre of Thessaloniki were evaluated using microscopic traffic simulation modelling. Results indicate that there would be a significant increase in fuel consumption and emissions if pedestrianization is implemented, both locally (i.e. along particular sections of roads) and network-wide. However, no assessment was made of the potential effects of pedestrianization on the demand of the public to travel and their choice of mode of travel that could result in changes in energy consumption and environmental conditions. Moreover, it has to be mentioned that emissions within pedestrianized areas cannot be estimated using microscopic traffic modelling.

\section{REFERENCES}

Chiquetto S, Mackett R (1995) Modelling the effects of transport policies on air pollution. Sci Total Environ 169: 265-271.

Chiquetto S (1997) The environmental impacts from the implementation of a pedestrianization scheme. Transport Res D-Tr E 2: 133-146.

Economou S, Tzevelekis I, Guitonas A (2002) Seeking for sustainability in urban renewal schemes: Measuring environmental impacts of restoration of Squares. Protection and restoration of the environment VI.
Ewing R (1999) Traffic Calming: State of the Practice. Institute of Transportation Engineers, Washington.

Ghafghazi G, Hatzopoulou M (2014) Simulating the environmental effects of isolated and area-wide traffic calming schemes using traffic simulation and microscopic emission modeling. Transportation, Springer.

Hall P, Hass-Klau C (1985) Can Rail Save the City? The Impacts of Rail Rapid Transit and Pedestrianizarion on British and German Cities. Gower, Aldershot.

Kepaptsoglou K, Karlaftis MG, Gkotsis I, Vlahogianni E, Stathopoulos A (2015) Urban regeneration in historic downtown areas: an ex-ante evaluation of traffic impacts in Athens, Greece. Int J Sustain Transp 9: 478-489.

Lockwood IM (1997) ITE Traffic calming definition. ITE J. 67: 22-24.

Madhava M, Coensel BD, Can A, Degraeuwe B, Beusen B, Vlieger ID, Botteldooren D (2011) Assessment of the impact of speed limit reduction and traffic signal coordination on vehicle emissions using an integrated approach. Transport Res D-Tr E 16: 504-508.

Mitsakis E, Stamos I, Salanova JM, Chrysochoou E, Iordanopoulos P, Aifadopoulou G (2013) Urban mobility indicators for Thessaloniki. JTLE 1: 148-152.

Papaioannou P, Basbas S, Parathira C (2000) Environmental impacts in Thessaloniki from alternative transportation measures and policies. J Environ Protect Ecol 1: 367-373.

Panis LI, Broekx S, Liu R (2006) Modelling instantaneous traffic emission and the influence of traffic speed limits. Sci Total Environ 371: 270-285.

Pitsiava-Latinopoulou M, Basbas S (2000) The impact of Pedestrianisation schemes on the Environmental quality at central areas, Proc. of the 6th International Conference "Urban Transport and the Environment in the 21st Century - Urban Transport VI", Wessex Institute of Technology, Cambridge, UK.

Rakha H, Kamalanathsharma RK (2011) Eco-driving at signalized intersections using V2I communication. 14th International IEEE Conference on Intelligent Transportation Systems, Washington, D.C., USA.

Stamos I, Salanova Grau JM, Mitsakis E (2013) Macroscopic Fundamental Diagrams: Simulation Findings for the road network of Thessaloniki. 6th International Congress on Transportation Research "Energy, Environment and Transport", Thessaloniki.

Taxiltaris C, Basbas S, Nikolaou K, Tzevelekis I (2002) Environmental impact assessment of major pedestrianization schemes through the use of modelling techniques. Fresen Environ Bull 11: 800-805. 